\title{
Characterization of Potential Virulence Factors of Vibrio mimicus Isolated from Fishery Products and Water
}

\author{
M. F. Hernández-Robles $\mathbb{D}^{1},{ }^{1}$ I. Natividad-Bonifacio $\mathbb{D}^{1},{ }^{1}$ A. K. Álvarez-Contreras $\mathbb{D}$, ${ }^{1}$ \\ J. J. Tercero-Alburo $\mathbb{D}^{1}{ }^{1}$ E. I. Quiñones-Ramírez $\mathbb{D}^{1}{ }^{1}$ and C. Vázquez-Salinas $\mathbb{D}^{2}$ \\ ${ }^{1}$ Departamento de Microbiología, Escuela Nacional de Ciencias Biológicas, \\ Instituto Politécnico Nacional,Prolongación Carpio y Plan de Ayala S/N, Ciudad de México, Colonia Santo Tomas, CP. 11340, \\ Mexico \\ ${ }^{2}$ Departamento de Biotecnología, División de Ciencias Biológicas y de la Salud, \\ Universidad Autónoma Metropolitana-Iztapalapa, Avenida San Rafael Atlixco 186, Ciudad de México, Colonia Vicentina, \\ C.P. 09340, Mexico
}

Correspondence should be addressed to C. Vázquez-Salinas; cvs@xanum.uam.mx

Received 10 February 2020; Revised 14 December 2020; Accepted 29 January 2021; Published 10 February 2021

Academic Editor: Simona Nardoni

Copyright (C) 2021 M. F. Hernández-Robles et al. This is an open access article distributed under the Creative Commons Attribution License, which permits unrestricted use, distribution, and reproduction in any medium, provided the original work is properly cited.

\begin{abstract}
Vibrio mimicus is a Gram-negative bacterium that is closely related to V. cholerae and causes gastroenteritis in humans due to contaminated fish consumption and seafood. This bacterium was isolated and identified from 238 analyzed samples of sea water, oysters, and fish. Twenty strains were identified as $V$. mimicus according to amplification of the $v m h A$ gene, which is useful as a marker of identification of the species. The production of lipases, proteases, and nucleases was detected; $45 \%$ of the strains were able to produce thermonucleases and $40 \%$ were capable of producing hydroxamate-type siderophores, and the fragment of the iuT gene was amplified in all of the $V$. mimicus strains. Seventy-five percent of $V$. mimicus strains showed cytopathic effect on Chinese hamster ovary $(\mathrm{CHO})$ cells and destruction of the monolayer, and $100 \%$ of the strains were adherent on the HEp- 2 cell line with an aggregative adherence pattern. The presence of virulence factors in $V$. mimicus strains obtained from fishery products suggests that another member of the Vibrio genus could represent a risk to the consumer due to production of different metabolites that allows it to subsist in the host.
\end{abstract}

\section{Introduction}

Vibrio mimicus is a Gram-negative bacterium that is closely related to $V$. cholerae and causes gastroenteritis characterized by diarrhea, nausea, vomiting, abdominal pain, and fever due to contaminated fish consumption and seafood $[1,2]$. The infective dose is unknown, but it is believed to be the same as that of $V$. cholerae, ranging from $10^{4}$ to $10^{6}$ cells [3]. This bacterium has been isolated from water and a variety of fishery products, such as oysters, sea turtle eggs, shrimp, crab, and fish [4].

The mechanisms of the pathogenicity of $V$. mimicus are unknown; however, it has been reported that $V$. mimicus produces several virulence factors, including adhesins, hemolysins, and various types of proteases (collagenases and metalloproteases), siderophores, cytolysins, lipases, and DNAses $[5,6]$. This bacterium produces a heat-labile cytolytic/hemolytic toxin called Vibrio mimicus hemolysin (VMH) encoded in $v m h A$ found in environment and clinical strains $[7,8]$. Thus, $v m h A$ gene is a useful marker of identification of this species [7].

It has been reported that $V$. mimicus shares some genotypic characteristics with $V$. cholerae such as the $\operatorname{ctx} \mathrm{AB}$ operon which encodes choleric toxin whose gene is found in the genome of bacteriophage СTXФ and infects $V$. cholerae, indicating horizontal transfer of this phage between $V$. cholerae and $V$. mimicus $[9,10]$.

There are several reports on infections due to $V$. mimicus in other countries, suggesting strains must harbor genes that can cause infections due to consuming raw or undercooked fishery 
products; however, there are no studies on the virulence markers that are harbored in wild-type strains. We showed the presence of some virulence factors in strains isolated from environmental samples.

\section{Materials and Methods}

A total of 238 samples were collected from 12 different sites (11 oysters, 11 fish, and 12 sea water samples per month) in the Pueblo Viejo Lagoon, Veracruz, México, for seven months (June to December 2017).

The species captured were white mullet (Mugil curema) and American oyster (Crassostrea virginica). Fish and oysters samples were transported in individually labeled and sealed plastic bags. Seawater samples were collected in labeled plastic jars. The samples were cooled at $4^{\circ} \mathrm{C}$ immediately after collection and transported to the laboratory for analysis.

\subsection{Isolation and Phenotypical Identification of $V$. mimicus.} $V$. mimicus was isolated and identified as described in the Bacteriological Analytical Manual of the Food and Drug Administration [11]. Each sample was homogenized (Stomacher ${ }^{\circledR} 400$ Circulator), $50 \mathrm{~g}$ was placed in $450 \mathrm{~mL}$ flasks containing alkaline peptone water (APW, $\mathrm{pH} 8.8$ ) to obtain duplicated dilutions from $1: 10,1: 100$, and $1: 1000$ and incubated at $37^{\circ} \mathrm{C}$ and $42^{\circ} \mathrm{C}$ for $6-24 \mathrm{~h}$. In water samples, $25 \mathrm{~mL}$ was homogenized in $225 \mathrm{ml}$ of alkaline peptone water and incubated for at least $6 \mathrm{~h}$ at $37^{\circ} \mathrm{C} \mathrm{[12].} \mathrm{Each} \mathrm{dilution} \mathrm{was}$ streaked onto thiosulfate-citrate-bile salts-sucrose agar plates and incubated at $37^{\circ} \mathrm{C}$ for $18-24 \mathrm{~h}$; three suspected $V$. mimicus colonies were selected from each plate. Halophilism tests were performed on tryptone agar containing $0,3,6,8$, and $10 \% \mathrm{NaCl}$. The API $20 \mathrm{E}$ system (BioMerieux ${ }^{\mathrm{TM}}$ ) and $v m h A$ amplification was used for identification.

Control strains used in this study were Vibrio mimicus ATCC 33653, Vibrio vulnificus ATCC 29307, Vibrio cholerae O1 Ogawa, Vibrio cholerae O1 Inaba, and Vibrio cholerae no O1 CLBM-ENCB.

2.2. Determination of the Proteolytic, Lipolytic, and Hemolytic Activities as well as Nuclease and Thermonuclease Production. Cells were grown overnight in tryptic soy agar with $2 \% \mathrm{NaCl}$ at $37^{\circ} \mathrm{C}$ and spot-inoculated onto the plated assay media as described by García and Landgraf [13]. Protease activity was determined using casein ( $2 \%$ skim milk) as substrate, and lipase activity was assessed in nutrient basal agar containing $10 \%(\mathrm{v} / \mathrm{v})$ egg yolk emulsion. To detect hemolysis, strains were streaked on blood agar with $5 \%$ sheep erythrocytes and blood agar with 5\% rabbit erythrocytes. To assess the presence of nucleases, $200 \mu \mathrm{L}$ of an overnight culture of $V$. mimicus was inoculated on DNAse agar [14]. For the thermonuclease assay, a fresh culture of $V$. mimicus was placed in a $100^{\circ} \mathrm{C}$ water bath for $10 \mathrm{~min}$, and then, $200 \mu \mathrm{L}$ of this culture was inoculated on wells of agar DNA with toluidine blue and incubated at $37^{\circ} \mathrm{C}$ for $6 \mathrm{~h}$ [15].
2.3. Presence of Siderophores. $V$. mimicus strains were incubated at $37^{\circ} \mathrm{C}$ for $18-24 \mathrm{~h}$ on nutrient broth, and afterwards, they were inoculated on chrome azurol S (CAS) agar [16]. V. mimicus ATCC 33653 was used as a positive control.

2.4. Assessment of the Cytotoxic Effect on Chinese Hamster Ovary Cells. V. mimicus strains were inoculated in AKI broth (peptone $15 \mathrm{~g} / \mathrm{L}$, yeast extract $4 \mathrm{~g} / \mathrm{L}$, and sodium chloride $5 \mathrm{~g} / \mathrm{L} \mathrm{pH} \mathrm{7.4)} \mathrm{and} \mathrm{incubated} \mathrm{for} 18 \mathrm{~h}$ with shaking $(5 \mathrm{~g})$ at $37^{\circ} \mathrm{C}$. The culture was centrifuged at $500 \mathrm{~g}$ for $10 \mathrm{~min}$, and the supernatant was filtered using a $0.22-\mu \mathrm{m}$ pore membrane. $V$. cholerae O1 Serotype Ogawa and Inaba were used as positive controls, and AKI broth without inoculum was used as a negative control. A total of $200 \mu \mathrm{L}$ of $\mathrm{CHO}$ suspension in F12 media with 15\% fetal bovine serum (SFB) was placed on each of the 96 wells of an ELISA plate. The plates were incubated at $37^{\circ} \mathrm{C}$ in a $5 \% \mathrm{CO}_{2}$ atmosphere until they reached $100 \%$ confluence. After the incubation time elapsed, media were discarded, and the plate was washed three times with sterile phosphate saline buffer (PBS). $100 \mu \mathrm{L}$ of $1: 1,1: 3,1: 9,1: 27,1: 81,1: 253,1: 729$, and $1: 2187$ dilutions per triplicate on F12 media of the filtrate of each one of the strains were added to each well and the plate was incubated at $35^{\circ} \mathrm{C}$ with $5 \% \mathrm{CO}_{2}$. The plates were observed under an inverted microscope every $60 \mathrm{~min}$ until the observation of alterations of $50 \%$ of monolayer cells. Cytopathic and cytotoxic effects were positive when more than $50 \%$ of the cells showed destruction or alterations in their morphology [5].

2.5. Adherence Assay on HEp-2 Cell Line. Adherence assays were performed in human laryngeal carcinoma cell (HEp-2) monolayers grown on coverslips in 24-well microtiter plates and grown to confluence at $37^{\circ} \mathrm{C}$ in $5 \% \mathrm{CO}_{2}$. Cell monolayers were inoculated in triplicate with $25 \mu \mathrm{L}$ of bacterial suspension. The plates were incubated at $37^{\circ} \mathrm{C}$ with a $5 \% \mathrm{CO}_{2}$ atmosphere for $1.5 \mathrm{~h}$, monolayers were then washed three times with PBS to remove nonadherent bacteria, and then the cells were fixed with methanol for $1 \mathrm{~min}$ and washed 3 times with sterile PBS and were Giemsa-stained for $20 \mathrm{~min}$. The wells were washed with distilled water, dehydrated with acetone-xylol, and sealed with a drop of Permount resin. Cells were observed under a microscope at 100x. Adherence assay was positive when more than $40 \%$ of the cells had adherent bacteria [5].

2.6. Genetic Analysis. A Wizard Genomic DNA Purification Kit (Promega, Madison, WI, USA) was used to obtain DNA. The reaction mixture was prepared with $34.95 \mu \mathrm{L}$ of distilled water, $5 \mu \mathrm{L}$ of $10 \mathrm{x}$ buffer $(200 \mathrm{mM}$ Tris- $\mathrm{HCl} \mathrm{pH} 8.4$ and $500 \mathrm{mM} \mathrm{KCl}), 2.5 \mu \mathrm{L}$ of $\mathrm{MgCl}_{2} 50 \mathrm{mM}, 0.25 \mu \mathrm{L}$ of a dNTP mixture $(10 \mathrm{mM}), 2.5 \mu \mathrm{L}$ of each primer $(1 \mathrm{nM}), 0.3 \mu \mathrm{L}$ of Taq polymerase $(5 \mathrm{U} / \mu \mathrm{L})$, and $2 \mu \mathrm{L}$ of the DNA containing solution (approximately $100 \mathrm{ng}$ ) in a final volume of $50 \mu \mathrm{L}$. PCR was performed on a MultiGene Gradient DNA Thermal Cycler MIDSCI with the primers and conditions reported in Tables 1 and 2. Obtained fragments were detected on agarose 
Table 1: :Primers used in this study.

\begin{tabular}{|c|c|c|}
\hline Target & Primer $\left(5^{\prime} \longrightarrow 3^{\prime}\right)$ & Reference \\
\hline$v m h A$ & $\begin{array}{c}\text { Fwd GGTAGYCATCAGTCTCATCACG } \\
\text { Rev TCRTSTCCCAATACTTCACCG }\end{array}$ & Present study \\
\hline $\operatorname{ctxA}$ & $\begin{array}{l}\text { Fwd CTCAGACGGGATTTGTTAGGCACG } \\
\text { Rev TCTATCTCTGTAGCCCCTATTACG }\end{array}$ & [7] \\
\hline $\operatorname{tcp} A$ & $\begin{array}{c}\text { Fwd GAAGAAGTTTGTAAAAGAAGAACAC } \\
\text { Rev GAAAGGACCTTCTTTCACGTTG }\end{array}$ & {$[17]$} \\
\hline toxR & $\begin{array}{l}\text { Fwd ACAACAGCGACTCCTCAGAA } \\
\text { Rev ACACACAGTTCTATCGAGGG }\end{array}$ & [7] \\
\hline iut & $\begin{array}{l}\text { Fwd AACCGCTACCAAATGACCCCAGAT } \\
\text { Rev CAAAACCGGCGACAGAACCTACTT }\end{array}$ & Present study \\
\hline
\end{tabular}

TABle 2: Conditions used for the detection of genes.

\begin{tabular}{|c|c|c|c|c|c|}
\hline Gene & $v m h A$ & $\operatorname{ctx} A$ & $t c p A$ & toxR & iut \\
\hline Initial denaturation & $95^{\circ} \mathrm{C} / 5 \mathrm{~min}$ & $95^{\circ} \mathrm{C} / 5 \mathrm{~min}$ & $95^{\circ} \mathrm{C} / 5 \mathrm{~min}$ & $95^{\circ} \mathrm{C} / 5 \mathrm{~min}$ & $95^{\circ} \mathrm{C} / 5 \mathrm{~min}$ \\
\hline Denaturation & $95^{\circ} \mathrm{C} / 45 \mathrm{~s}$ & $95^{\circ} \mathrm{C} / 45 \mathrm{~s}$ & $95^{\circ} \mathrm{C} / 45 \mathrm{~s}$ & $95^{\circ} \mathrm{C} / 45 \mathrm{~s}$ & $95^{\circ} \mathrm{C} / 45 \mathrm{~s}$ \\
\hline Annealing & $58^{\circ} \mathrm{C} / 45 \mathrm{~s}$ & $55^{\circ} \mathrm{C} / 30 \mathrm{~s}$ & $57^{\circ} \mathrm{C} / 40 \mathrm{~s}$ & $51^{\circ} \mathrm{C} / 45 \mathrm{~s}$ & $62^{\circ} \mathrm{C} / 1 \mathrm{~min}$ \\
\hline Extension & $72^{\circ} \mathrm{C} / 45 \mathrm{~s}$ & $72^{\circ} \mathrm{C} / 45 \mathrm{~s}$ & $72^{\circ} \mathrm{C} / 45 \mathrm{~s}$ & $72^{\circ} \mathrm{C} / 45 \mathrm{~s}$ & $72^{\circ} \mathrm{C} / 1 \mathrm{~min}$ \\
\hline Amplicon size (bp) & 389 & 301 & 472 & 221 & 1573 \\
\hline
\end{tabular}

gels that were observed on Bio-Imagen Systems ${ }^{\circledR}$. Images were digitalized with the MBE-IMG ${ }^{\circledR}$ (Mayor Science ${ }^{\circledR}$ ) program.

\section{Results and Discussion}

Of the 238 analyzed samples, a total of 1455 colonies with characteristics of the genus Vibrio were phenotypically identified, and only 20 were confirmed as $V$. mimicus ( 6 were isolated from sea water samples, 10, from oysters, and 4, from fish) by API 20E and genotypically by $v m h A$ amplification (Figure 1). V. mimicus infections have been associated with gastroenteritis after seafood ingestion due to the fact that, in different countries, it is customary that oysters are to be eaten straight from the valves [18]. In fact, almost all reported cases are related to bivalves consumption as the source of direct contamination and/or turtle eggs as a crosscontamination $[19,20]$. Additionally, fish is consumed without any thermic treatment like "ceviche," a typical raw seafood dish where only lemon is added; these cultural traditions performed in holiday seasons are risk factors to contract diseases related to this bacterial genus.

All analyzed strains produced $\beta$ hemolysis on sheep and rabbit erythrocytes (Table 3); Alam [21] and Beshiru [22] obtained $80 \%$ of hemolytic strains. Similarly, Miyoshi [23] reported that $V$. mimicus lyses horse, sheep, and human erythrocytes. The main hemolysin presence in this species is $\mathrm{VMH}$, which showed $76 \%$ homology with the hlyA of $V$. cholerae el Tor; $\mathrm{VMH}$ is capable of forming pores on the cell surface and also promotes the production of cAMP, causing diarrhea $[24,25]$.

$v m h A$ gene is considered a specific gene, and it is found in the wild-type and clinical strains [7]. Wei et al. [26] showed that gene amplification is correlated with other identification techniques as fatty acids profiles and $16 \mathrm{~S}$ $D N A r$, oriC, $p y r H, r e c A$, and $r p o A$ gene sequences

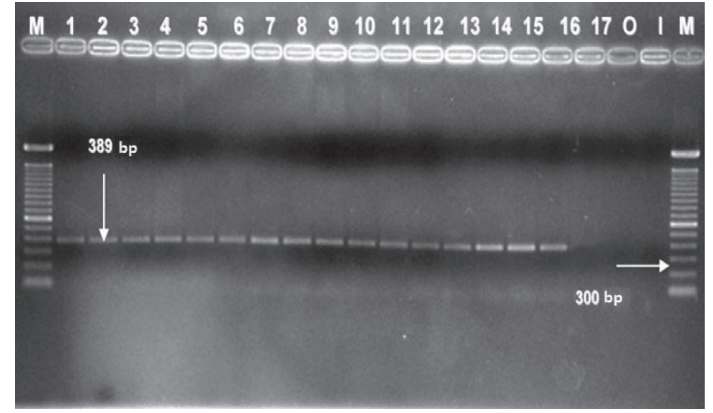

FIGURE 1: Electrophoresis gel of $v m h A$ gene amplification product. Lanes (M): $100 \mathrm{bp}$ molecular weight marker; lanes 1-15: isolated strains of V. mimicus; lane 16: V. mimicus ATCC 33653; lane 17: Vibrio vulnificus ATCC 29307; lane (O): V. cholerae O1 Ogawa; lane (I): $V$. cholerae O1 Inaba.

comparison. In this study, $v m h$ gene was amplified in all work strains (Table 3).

Regarding the enzymatic testing, all strains were positive for the production of lipases and proteases, and only $45 \%$ of the strains were positive for thermonuclease production. These results are similar to those reported by Alam [20], which showed that $95 \%$ of $V$. mimicus strains were positive for protease production. Beshiru [21] showed that $90 \%$ of their $V$. mimicus isolated were positive to protease activity. It has been reported that bacterial proteases are an extensive collection of enzymes that have important roles in pathogenicity, stress response, and cell viability [27-29].

All of the isolated strains in this study had lipolytic activity. These results are similar to those reported by Beshiru [22]. Davis [30] indicated that only $10 \%$ were positive for lipase activity at 48 hours, and Fiore [31] indicated that $95 \%$ of $V$. mimicus strains had a lipase activity. The presence of DNAses was observed in $45 \%$ of the isolated strains of $V$. mimicus. Beshiru [22] reported that $100 \%$ of 
TABLe 3: Genotypic and phenotypic results of working strains.

\begin{tabular}{|c|c|c|c|c|c|c|c|c|c|c|c|}
\hline Strain & Origin & $\beta$-Hemolysis & $v m h$ & Siderophore & iut & $c t x$ & $t c p A$ & toxR & Cytotoxicity & Titer of the filtrates & Adherence \\
\hline $\mathrm{Vm}$ & ATCC & + & + & + & + & - & - & + & + & $1: 27$ & + \\
\hline 1 & $W$ & + & + & - & + & - & - & + & + & $1: 27$ & + \\
\hline 2 & $W$ & + & + & - & + & - & - & + & + & $1: 27$ & + \\
\hline 3 & $O$ & + & + & + & + & - & - & + & + & $1: 27$ & + \\
\hline 4 & $O$ & + & + & - & + & - & - & + & + & $1: 27$ & + \\
\hline 5 & $F$ & + & + & + & + & - & - & + & - & $1: 9$ & + \\
\hline 6 & $F$ & + & + & + & + & - & - & + & - & $1: 3$ & + \\
\hline 7 & $F$ & + & + & + & + & - & - & + & + & $1: 81$ & + \\
\hline 8 & $W$ & + & + & - & + & - & - & + & + & $1: 81$ & + \\
\hline 9 & $W$ & + & + & - & + & - & - & + & + & $1: 81$ & + \\
\hline 10 & $W$ & + & + & + & + & - & - & + & - & $1: 3$ & + \\
\hline 11 & $W$ & + & + & - & + & - & - & + & - & $1: 3$ & + \\
\hline 12 & $O$ & + & + & - & + & - & - & + & + & $1: 27$ & + \\
\hline 13 & $O$ & + & + & - & + & - & - & + & + & $1: 81$ & + \\
\hline 14 & $O$ & + & + & - & + & - & - & + & + & $1: 81$ & + \\
\hline 15 & $O$ & + & + & + & + & - & - & + & - & $1: 9$ & + \\
\hline 16 & $O$ & + & + & - & + & - & - & + & + & $1: 27$ & + \\
\hline 17 & $F$ & + & + & + & + & - & - & + & + & $1: 27$ & + \\
\hline 18 & $O$ & + & + & - & + & - & - & + & + & $1: 27$ & + \\
\hline 19 & $O$ & + & + & + & + & - & - & + & + & $1: 27$ & + \\
\hline 20 & $O$ & + & + & - & + & - & - & + & + & $1: 27$ & + \\
\hline
\end{tabular}

$W=$ sea water $O=$ oyster; $F=$ fish.

their strains produce DNAses. Pathogens produce nucleases that can degrade extracellular DNA as a mean of escape and spread through tissues. Currently, the majority of $V$. vulnificus and $V$. cholerae strains are positive for DNA destruction [32,33]. It is known that $V$. cholerae DNAse is secreted to the surrounding environment [34].

3.1. Detection of $c t x A, \operatorname{tcp} A$, and toxR Genes. Fragments of the $c t x A$ and $t c p A$ genes could not be amplified in any of the studied strains of $V$. mimicus (Table 3 ). The absence of these two genetic elements is consistent with the report from Shinoda [7], which indicated that the presence of a phage in $V$. mimicus strains of environmental origin is lower than $1 \%$ $[20,34]$. There are V. mimicus strains, in which VPI1 is incomplete; these strains lack the gene that encodes the structural protein of the TCP pilus $(t c p A)$ or do not possess the tox $T$ regulator gene $[7,24]$.

In $100 \%$ of the studied strains, the toxR gene was amplified (Table 3) (Figure 2). Shinoda [7] and Provenzano [35] indicated that this gene is present in all species of the Vibrio genus. This gene encodes a transmembrane protein that regulates many of the virulence functions in $V$. mimicus and $V$. cholerae; its presence allows $V$. mimicus to regulate its own virulence functions and change the external membrane protein expression pattern in response to environmental stimuli, favoring intestinal colonization, hemolysin expression and flagella mobility [36]. This protein is capable of regulating genes that are present in the pathogenicity island and those of the phage [17].

3.2. Siderophores. A total of $40 \%$ of the strains were capable of producing hydroxamate-type siderophores in the CAS agar, and we found that all of the working strains contain the

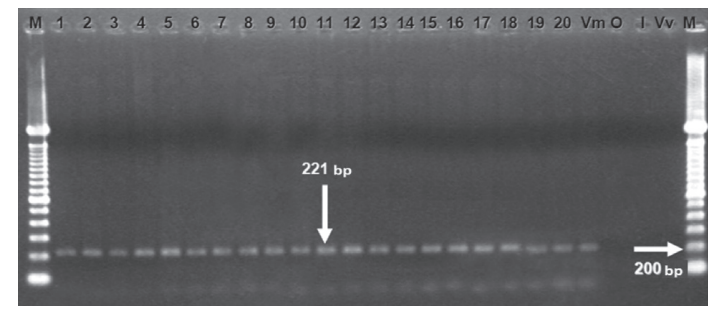

FIGURE 2: Electrophoresis gel of toxR gene amplification product. Lanes (M): $100 \mathrm{bp}$ molecular weight marker; lane 1: $V$. mimicus ATCC 33653; lanes 2-20: isolated strains of V. mimicus; lane $(\mathrm{O})$ : $V$. cholerae O1 Ogawa; lane (I): V. cholerae O1 Inaba; lane (Vv): V. vulnificus ATCC 29307.

iut T gene (Table 3) (Figure 3). It has been reported that $V$. mimicus produces aerobactin in response to iron deprivation, and the operon iucABCD iutA is involved in the synthesis of this hydroxamate-type siderophore [37].

Even though we found iut T gene in $100 \%$ of the strains, not all of them were capable of producing siderophores. The toxicity of some components in the CAS medium has been reported and can inhibit the growth of some microorganisms [38]. There are not enough reports about the prevalence of iutT gene in V. mimicus; nevertheless, Moon [39] found the aerobactin operon in the clinical and environmental $V$. mimicus strains. Besides, these authors suggest that these genes are located on the bacterial chromosome and are widely distributed among strains of this species.

It is worth mentioning that the role of siderophores as virulence factors is questioned in other species such as Klebsiella pneumoniae, Shigella spp., and invasive Escherichia coli that lost their pathogenicity when the aerobactin operon is lost. This fact shows that the iron intake mechanisms are a key factor in the process of host infection [40]. 


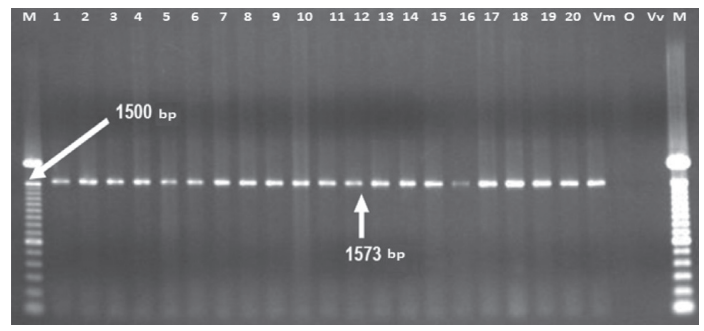

Figure 3: Electrophoresis gel of $i u T$ gene amplification product. Lanes (M): 100 bp molecular weight marker; lanes 1-20: isolated strains of V. mimicus; lane (Vm): V. mimicus ATCC 33653; lane (O) V. cholerae O1 Ogawa; lane (Vv): V. vulnificus ATCC 29307.

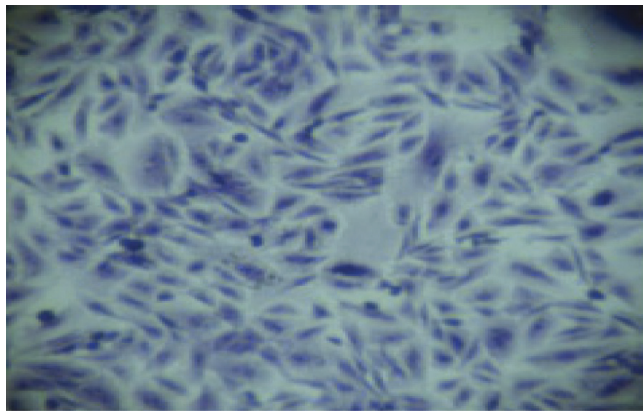

(a)

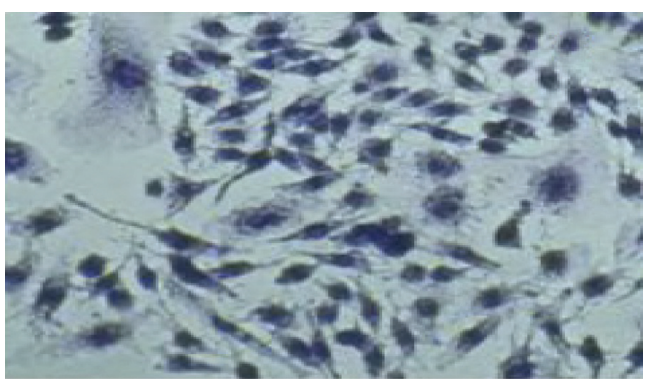

(c)

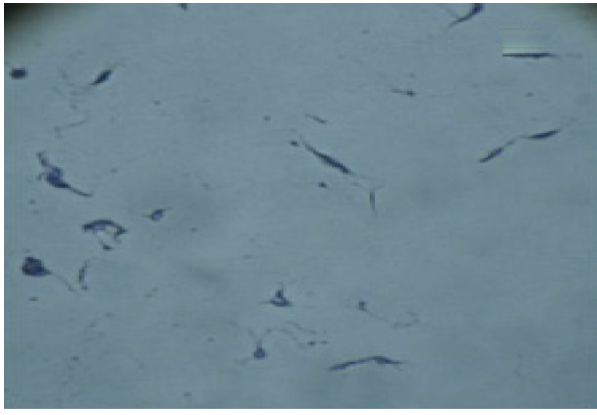

(b)

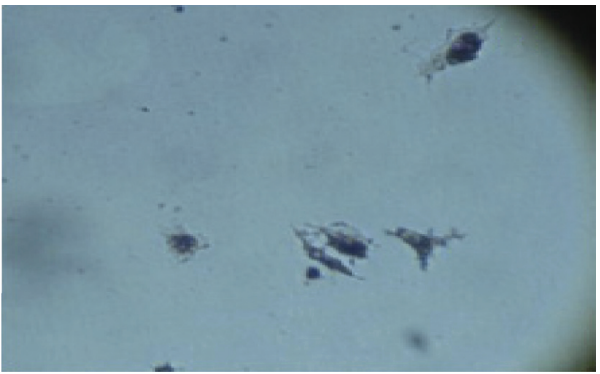

(d)

FIgure 4: Cytotoxicity assay on CHO cell line. (a) CHO cell control. (b) Positive control with V. cholerae O1 serotype Ogawa filtrate. (c) Cytopathic effect caused by V. mimicus filtrates after three hours of exposure. (d) Destruction of the cell monolayer caused by the $V$. mimicus filtrates after six hours of exposure (inverted microscope 40X).

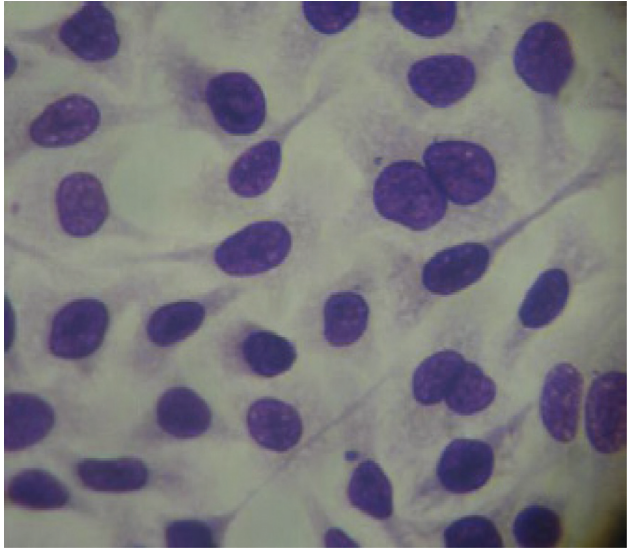

(a)

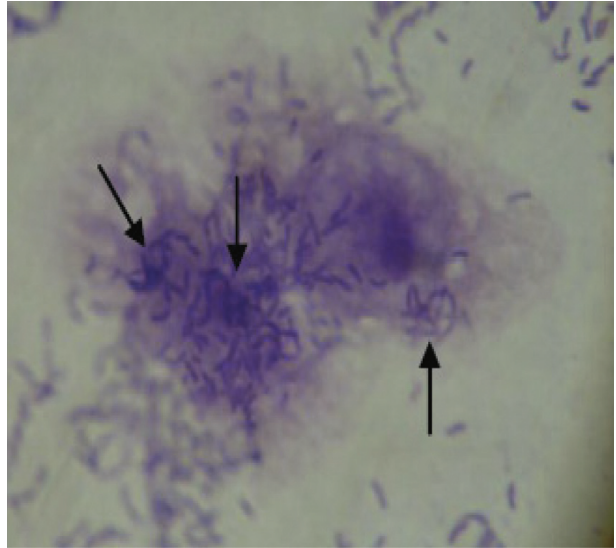

(b)

Figure 5: Adherence of V. mimicus to HEp-2 cells. (a) Negative control, HEp-2 cells. (b) Adherence pattern exhibited by the V. mimicus strains (light microscope 100X). 
3.3. Effect of the Cell-Free Filtrates on the CHO Cell Line. Seventy-five percent of all $V$. mimicus strains (15/20) showed a cytopathic effect within $3 \mathrm{~h}$ and monolayer destruction after $6 \mathrm{~h}$ (Figure 4 ). The rest (25\%) only showed a cytopathic effect characterized by cell loss of structure. The titer of the filtrates of $V$. mimicus ranged from $1: 3$ to $1: 81$, and there is no precedent for estimating their activity. Nevertheless, Baffone [5] found that $V$. alginolyticus, V. parahaemolyticus, and $V$. cholerae no $\mathrm{O} 1$ filtrates had titers ranging from $1: 4$ to $1: 10$, considering that the latter strains are highly cytotoxic. Bag [41] reported that isolates of $V$. cholerae no O1/no O139 present titers ranging from $1: 4$ to $1: 128$.

In our study, we found that a titer below $1: 9$ results in a cytopathic phenotype, whereas, with a higher titer, the effect is cytotoxic reaching $1: 81$. The difference among the titers might be caused by variations in the expression of the hemolysins that are the most common cause of destruction and cell damage effect produced by Vibrio genus [41].

3.4. Adherence Assay. We found that $100 \%$ (20/20) of the strains were adherent (Figure 5). These results concur with previous reports $[21,42,43]$, describing $V$. mimicus in a multifactorial adherence process on the surface of intestinal cells in mice [43].

\section{Conclusions}

In this study, we find virulence factors in $V$. mimicus strains as shown for other vibrios. These determinants may enable the microorganism to invade the host and cause tissue damage in order to access nutrient sources required for its growth and propagation. The fishery products contaminated with $V$. mimicus might be a risk if consumed raw or undercooked because it could cause gastroenteritis outbreaks; its ability to adapt to environmental changes and production of different metabolites is what allows it to subsist in the host. This finding leads us to suggest further research to determine the presence of other potential $V$. mimicus virulence factors. Studies on virulence factors in other species of the Vibrio genus offer information that could be used to understand the pathogenicity of this bacterium.

\section{Data Availability}

The data used to support the findings of this study are included within the article.

\section{Conflicts of Interest}

The authors declare that there are no conflicts of interest regarding the publication of this article.

\section{Acknowledgments}

The authors thank Instituto Politécnico Nacional and Universidad Autónoma Metropolitana for the financial support.

\section{References}

[1] T. Mizuno, S. Z. Sultan, Y. Kaneko et al., "Modulation of Vibrio mimicus hemolysin through limited proteolysis by an endogenous metalloprotease," FEBS Journal, vol. 276, no. 3, pp. 825-834, 2009.

[2] M. K. Kay, E. J. Cartwright, D. Maceachern et al., "Vibrio mimicus infection associated with crayfish consumption, Spokane, Washington, 2010," Journal of Food Protection, vol. 75, no. 4, pp. 762-764, 2012.

[3] T. Ramamurthy and G. B. Nair, "Foodborne pathogenic vibrios," Infectious Disease: Foodborne Diseases, pp. 115-156, Humana Press, Totowa, NJ, USA, 2007.

[4] I. Guardiola-Avila, E. Acedo-Felix, I. Sifuentes-Romero, G. Yepiz-Plascencia, B. Gomez-Gil, and L. Noriega-Orozco, "Molecular and genomic characterization of Vibrio mimicus isolated from a frozen shrimp processing facility in Mexico," PLoS One, vol. 11, Article ID e0144885, 2016.

[5] W. Baffone, B. Citterio, E. Vittoria et al., "Determination of several potential virulence factors in Vibrio spp. isolated from sea water," Food Microbiology, vol. 18, no. 5, pp. 479-488, 2001.

[6] D. V. Singh, S. R. Isac, and R. R. Colwell, "Development of a hexaplex PCR assay for rapid detection of virulence and regulatory genes in Vibrio cholerae and Vibrio mimicus," Journal of Clinical Microbiology, vol. 40, no. 11, pp. 4321-4324, 2002.

[7] S. Shinoda, T. Nakagawa, L. Shi et al., "Distribution of virulence-associated genes inVibrio mimicusIsolates from clinical and environmental origins," Microbiology and Immunology, vol. 48, no. 7, pp. 547-551, 2004.

[8] S.-I. Miyoshi, H. Ikehara, M. Kumagai, T. Mizuno, T. Kawase, and Y. Maehara, "Defensive effects of human intestinal antimicrobial peptides against infectious diseases caused by Vibrio mimicus and V. vulnificus," Biocontrol Science, vol. 19, no. 4, pp. 199-203, 2014.

[9] E. F. Boyd, K. E. Moyer, L. Shi, and M. K. Waldor, "Infectious СТХ $\Phi$ and the Vibrio pathogenicity island prophage in Vibrio mimicus: evidence for recent horizontal transfer between V. Mimicus and V. cholerae," Infection and Immunity, vol. 68, no. 3, pp. 1507-1513, 2000.

[10] D. Wang, H. Wang, Y. Zhou et al., "Genome sequencing reveals unique mutations in characteristic metabolic pathways and the transfer of virulence genes between $V$. mimicus and V. cholerae," PLoS One, vol. 6, Article ID e0021299, 2011.

[11] A. De Paola and C. A. Kaysner, Bacteriological Analytical Manual, Vibrio. Food Science and Research, pp. 1-19, U. S. Food and Drug Administration, Washington, DC, 2004.

[12] M. Paydar and K. L. Thong, "Prevalence and genetic characterization of Vibrio vulnificus in raw seafood and seawater in Malaysia," Journal of Food Protection, vol. 76, no. 10, pp. 1797-1800, 2013.

[13] M. L. G. Moreno and M. Landgraf, "Virulence factors and pathogenicity of Vibrio vulnificus strains isolated from seafood," Journal of Applied Microbiology, vol. 84, no. 5, pp. 747-751, 1998.

[14] P. A. West and R. R. Colwell, "Identification and classification of Vibrionaceae - an overview," Vibrios in the Environment, pp. 285-363, Wiley-Interscience, New York, NY, USA, 1984.

[15] R. V. F. Lachica, C. Genigeorgis, and P. D. Hoeprich, "Metachromatic agar-diffusion methods for detecting staphylococcal nuclease activity," Applied Microbiology, vol. 21, no. 4, pp. 585-587, 1971. 
[16] B. Schwyn and J. B. Neilands, "Universal chemical assay for the detection and determination of siderophores," Analytical Biochemistry, vol. 160, no. 1, pp. 47-56, 19879.

[17] M. S. Islam, M. Z. Rahman, S. I. Khan et al., "Organization of the CTX prophage in environmental isolates ofVibrio mimicus," Microbiology and Immunology, vol. 49, no. 8, pp. 779-784, 2005.

[18] C. Pruzzo, G. Gallo, and L. Canesi, "Persistence of vibrios in marine bivalves: the role of interactions with haemolymph components," Enviromental Microbiology, vol. 7, no. 6, pp. 761-772, 2005.

[19] P. Pérez, R. Mejias, and M. Rivero, "Vibrio mimicus Gastroenteritis report of two cases," Revista espanola de enfermedades digestivas, vol. 93, pp. 1-61, 2001.

[20] E. Campos, H. Bolaños, M. T. Acuña et al., "Vibrio mimicus diarrhea following ingestion of raw turtle eggs," Applied and Environmental Microbiology, vol. 62, no. 4, pp. 1141-1144, 1996.

[21] M. Alam, S. Miyoshi, S. Yamamoto, K. Tomochika, and S. Shinoda, "Expression of virulence-related properties by, and intestinal adhesiveness of, Vibrio mimicus strains isolated from aquatic environments," Applied and Environmental Microbiology, vol. 62, no. 10, pp. 3871-3874, 1996.

[22] A. Beshiru and E. O. Igbinosa, "Characterization of extracellular virulence properties and biofilm-formation capacity of Vibrio species recovered from ready-to-eat (RTE) shrimps," Microbial Pathogenesis, vol. 119, pp. 93-102, 2018.

[23] S. Miyoshi, K. Sasahara, S. Akamatsu et al., "Purification and characterization of a hemolysin produced by Vibrio mimicus," Infection and Immunity, vol. 65, no. 5, pp. 1830-1835, 1997.

[24] K. Bi, S.-I. Miyoshi, K.-I. Tomochika, and S. Shinoda, "Detection of virulence associated genes in clinical strains ofVibrio mimicus," Microbiology and Immunology, vol. 45, no. 8, pp. 613-616, 2001.

[25] Y. Li, K. Okamoto, E. Takahashi et al., "A hemolysin ofVibrio mimicus(VMH) stimulates cells to produce ATP and cyclic AMP which appear to Be secretory mediators," Microbiology and Immunology, vol. 49, no. 1, pp. 73-78, 2005.

[26] S. Wei, L. L. Chern, Y. C. Wu, Y. L. Wang, C. M. Lin, and C. S. Chiou, "Foodborne disease outbreaks caused by sucrosenonfermenting and $\beta$-galactosidase-deficient variants of Vibrio cholerae," International Journal of Food Microbiology, vol. 122, no. 1-2, pp. 148-155, 2008

[27] E. Culp and G. D. Wright, "Bacterial proteases, untapped antimicrobial drug targets," The Journal of Antibiotics, vol. 70, no. 4 , pp. 366-377, 2017.

[28] L. Jong-Hee, A. Sun-Hee, L. Eun-Mi, J. Seung-Ha, K. YoungOk, L. Sang-Jun et al., "The FAXWXXT motif in the carboxyl terminus of Vibrio mimicus metalloprotease is involved in binding to collagen," FEBS Letter, vol. 579, pp. 2507-2513, 2005.

[29] M. A. Chowdhury, S. Miyoshi, and S. Shinoda, "Role of Vibrio mimicus protease in enterotoxigenicity," Journal of Diarrhoeal Diseases Research, vol. 9, no. 4, pp. 332-334, 1991.

[30] B. R. Davis, G. R. Fanning, J. M. Madden et al., "Characterization of biochemically atypical Vibrio cholerae strains and designation of a new pathogenic species, Vibrio mimicus," Journal of Clinical Microbiology, vol. 14, no. 6, pp. 631-639, 1981.

[31] A. E. Fiore, J. M. Michalski, R. G. Russell, C. L. Sears, and J. B. Kaper, "Cloning, characterization, and chromosomal mapping of a phospholipase (lecithinase) produced by Vibrio cholerae," Infection and Immunity, vol. 65, no. 8, pp. 3112-3117, 1997.
[32] D. P. Rodrigues, R. V. Ribeiro, R. V. Ribeiro, and E. Hofer, "Analysis of some virulence factors ofVibrio vulnificusisolated from Rio de Janeiro, Brazil," Epidemiology and Infection, vol. 108, no. 3, pp. 463-467, 1992.

[33] T. Focareta and P. A. Manning, "Distinguishing between the extracellular DNases of Vibrio cholerae and development of a transformation system," Molecular Microbiology, vol. 5, no. 10 , pp. 2547-2555, 1991.

[34] M. T. Acuña, G. Díaz, H. Bolaños et al., "Sources of Vibrio mimicus contamination of turtle eggs," Applied and Environmental Microbiology, vol. 65, no. 1, pp. 336-338, 1999.

[35] D. Provenzano, D. A. Schuhmacher, J. L. Barker, and K. E. Klose, "The virulence regulatory protein ToxR mediates enhanced bile resistance in Vibrio cholerae and other PathogenicVibrio species," Infection and Immunity, vol. 68, no. 3 , pp. 1491-1497, 2000.

[36] K. Skorupski and R. K. Taylor, "Control of the ToxR virulence regulon in Vibrio cholerae by environmental stimuli," Molecular Microbiology, vol. 25, no. 6, pp. 1003-1009, 1997.

[37] N. Okujo and S. Yamamoto, "Identification of the siderophores fromVibrio hollisaeandVibrio mimicusas aerobactin," FEMS Microbiology Letters, vol. 118, no. 1-2, pp. 187-192, 1994.

[38] S. Pérez-Miranda, N. Cabirol, R. George-Téllez, L. S. Zamudio-Rivera, and F. J. Fernández, "O-CAS, a fast and universal method for siderophore detection," Journal of Microbiological Methods, vol. 70, no. 1, pp. 127-131, 2007.

[39] Y.-H. Moon, T. Tanabe, T. Funahashi, K.-i. Shiuchi, H. Nakao, and S. Yamamoto, "Identification and characterization of two contiguous operons required for aerobactin transport and biosynthesis inVibrio mimicus," Microbiology and Immunology, vol. 48, no. 5, pp. 389-398, 2004.

[40] H. Schinid and M. Hensel, "Pathogenicity islands in bacterial pathogenesis," Clin. Microbiol. Rev.vol. 17, pp. 14-56, 2004.

[41] P. K. Bag, P. Bhowmik, T. K. Hajra et al., "Putative virulence traits and pathogenicity of Vibrio cholerae non-O1, non-O139 isolates from surface waters in Kolkata, India," Applied and Environmental Microbiology, vol. 74, no. 18, pp. 5635-5644, 2008.

[42] M. Alam, S. Miyoshi, K. Tomochika, and S. Shinoda, "Vibrio mimicus attaches to the intestinal mucosa by outer membrane hemagglutinins specific to polypeptide moieties of glycoproteins," Infection and Immunity, vol. 65, no. 9, pp. 3662-3665, 1997.

[43] M. Alam, S. Miyoshi, K. U. Ahmed, N. A. Hasan, K. Tomochika, and S. Shinoda, "Proteolytic activation ofVibrio mimicus $(\mathrm{Vm})$ major outer membrane protein haemagglutinin (HA) with Vm-HA/protease: implication for understanding bacterial adherence," Microbiology and Immunology, vol. 50, no. 11, pp. 845-850, 2006. 